\title{
Deiksis Persona dalam Buku Ajar BIPA Sahabatku Indonesia Tingkat B2
}

\author{
Durrah Nafisah $^{\text {a,1, }}$, Liliana Muliastuti ${ }^{\text {a,2, }}$, Nuruddin ${ }^{\text {a,3 }}$ \\ ${ }^{a}$ Universitas Negeri Jakarta, Jakarta, Indonesia \\ Idurrahnafisah@gmail.com; ${ }^{2}$ lilianamuliastuti@unj.ac.id; ${ }^{3}$ nuruddin@unj.ac.id
}

\begin{tabular}{l}
\hline Article info \\
\hline Article history: \\
Received: $22-10-2019$ \\
Revised : 20-01-2020 \\
Accepted: $14-03-2020$
\end{tabular}

Keywords:

$B I P A$

level B2

personal deixis

textbook

qualitative approach

\section{A B S T R A C T}

In the BIPA Sahabatku Indonesia textbook, competency mapping about personal deixis has been taught at the Al level. However, in reality, BIPA level B2 learners still use person deixis incorrectly. In fact, persona deixis is closely used in daily life. This study aims to: (1) find out how person deixis in the BIPA Sahabatku Indonesia textbook level B2 and (2) find out how the deixis rhetoric in the BIPA Sahabatku Indonesia B2 level textbook. This research uses content analysis with a qualitative approach. The number of types of person deixis in the BIPA Sahabatku Indonesia textbook level B2 is 102 data. The data consists of 55 data (53.92\%) first-person deixis, 4 data (3.92\%) plural first person deixis, 29 data (28.43\%) second persona single deixis, 0 (0\%) person deixis second plural, 8 data (7.84\%) third single person deixis, and 6 data (5.88\%) plural third-person deixis. Meanwhile, deixis rhetoric in the B2 level Sahabatku textbooks has 71 data.

Dalam buku ajar BIPA Sahabatku Indonesia, pemetaan kompetensi tentang deiksis persona sudah diajarkan pada tingkat A1. Namun, kenyataannya pemelajar BIPA tingkat B2 masih salah menggunakan deiksis persona. Padahal, deiksis persona erat digunakan dalam kehidupan sehari-hari. Penelitian ini bertujuan untuk: (1) mengetahui bagaimana deiksis persona dalam buku ajar BIPA Sahabatku Indonesia tingkat B2 dan (2) mengetahui bagaimana retorika deiksis dalam buku ajar BIPA Sahabatku Indonesia tingkat B2. Penelitian ini menggunakan analisis isi dengan pendekatan kualitatif. Jumlah jenis-jenis deiksis persona dalam buku ajar BIPA Sahabatku Indonesia tingkat B2 adalah 102 data. Data tersebut terdiri atas 55 data $(53,92 \%)$ deiksis persona pertama tunggal, 4 data $(3,92 \%)$ deiksis persona pertama jamak, 29 data $(28,43 \%)$ deiksis persona kedua tunggal, $0(0 \%)$ deiksis persona kedua jamak, 8 data $(7,84 \%)$ deiksis persona ketiga tunggal, dan 6 data $(5,88 \%)$ deiksis persona ketiga jamak. Sementara itu, retorika deiksis dalam buku ajar Sahabatku Indonesia tingkat $\mathrm{B} 2$ ada 71 data.

Copyright @ 2020 Institut Agama Islam Negeri Syekh Nurjati Cirebon. All rights reserved.

\section{PENDAHULUAN}

Pengajaran BIPA saat ini sedang kekinian. Salah satu faktor pendukung dalam pengajaran BIPA adalah dengan memilih buku ajar yang sesuai dengan kebutuhan si pemelajar (Fariqoh, 2016). Dalam buku ajar BIPA Sahabatku Indonesia, pemetaan kompetensi tentang deiksis persona sudah diajarkan pada tingkat A1. Namun, kenyataannya pemelajar BIPA tingkat B2 masih salah menggunakan deiksis persona. Padahal, deiksis persona erat digunakan dalam 
kehidupan sehari-hari. Urgensi penelitian ini untuk menambah wawasan tentang pragmatik dan menjadi masukan kepada penulis bahwa materi deiksis penting dimasukkan dalam buku ajar. Tujuan penelitian ini untuk mengetahui jenis-jenis deiksis persona dan retorika deiksis dalam buku ajar BIPA Sahabatku Indonesia tingkat B2.

Dalam pembelajaran bahasa Indonesia terdapat empat keterampilan yang harus dikuasai. Keempat keterampilan tersebut antara lain menyimak, berbicara, membaca, dan menulis. Keempat keterampilan tersebut terbagi menjadi keterampilan yang reseptif dan produktif. Keterampilan menyimak dan membaca melatih seseorang untuk mendapatkan informasi atau pesan yang terdapat dalam tulisan (Suyitno, 2007). Pendengar atau pembaca mendapatkan informasi tanpa menghasilkan suatu produk bacaan baru. Oleh sebab itu, keterampilan menyimak dan membaca termasuk ke dalam keterampilan reseptif.

Keterampilan menyimak dan membaca termasuk pendekatan reseptif sedangkan keterampilan berbicara dan menulis termasuk ke dalam keterampilan produktif. Kedua keterampilan tersebut melatih pembicara dan penulis untuk menghasilkan suatu produk baik berupa teks atau tulisan. Keterampilan menulis sering dianggap sebagai keterampilan yang paling kompleks. Dalam proses keterampilan menulis, penulis harus mampu mendeskripsikan pemikirannya dengan baik. Penulis harus mampu menulis dengan memikirkan beberapa aspek yang harus ditulisnya sehingga tidak salah jika keterampilan menulis sering dikaitkan dengan keterampilan membaca. Seseorang yang memiliki referensi bacaan yang banyak dan baik kemungkinan besar kemampuan menulisnya juga baik.

Keterampilan menulis merupakan keterampilan berbahasa paling akhir yang dikuasai oleh seseorang setelah menguasai keterampilan menyimak, berbicara, dan membaca (Mulyaningsih, Suwandi, Setiawan, \& Rohmadi, 2018). Keterampilan menulis juga bukanlah sekadar keterampilan menyalin kata, frasa, ataupun kalimat, melainkan juga keterampilan dalam mengembangkan dan menuangkan pikiran penulis dalam suatu struktur tulisan yang teratur dan tepat. Karena diaggap sebagai keterampilan yang paling kompleks, banyak tulisan meniru atau mem-plagiat hasil karya orang lain. Plagiasi terjadi dikarenakan pembaca yang tidak memiliki referensi bacaan untuk ditulis. Hal ini membuat pembaca sulit mengungkapkan hal yang akan disampaikan. Informasi yang dimiliki pembaca tidak banyak sehingga pembaca mengulang kembali informasi tanpa mencantumkan sumber.

Penulisan ide seseorang tanpa penulisan sumber penulis aslinya berakibat dengan plagiasi. Secara tidak langsung, penulis menyatakan bahwa pernyataan yang ditulisnya merupakan pernyataan yang dibuatnya sendiri. Intinya, plagiasi dapat terjadi karena kemampuan literasi menulis yang rendah. Hal tersebut senada dengan pernyataan bahwa budaya literasi diarahkan untuk melakukan kebiasaan berpikir. Kebiasaan berpikir tersebut diwujudkan dengan kegiatan membaca dan menulis yang akhirnya akan menghasilkan suatu karya.

Hasil tes dan survei PISA (Programme for International Student Assesment) pada tahun 2015 melibatkan 540.000 siswa di 70 negara. Singapura adalah negara yang menduduki peringkat 1 untuk ketiga materi, yaitu: sains, membaca, dan matematika. Indonesia meraih peringkat 64 dari 65 negara (TIMSS \& PIRLS, 2019). Survei PISA yang dilakukan untuk tingkat pendidikan dasar dapat menjadi cerminan atau gambaran umum mengenai kegiatan literasi membaca dan menulis 
peserta didik. Berdasarkan survei dan tes PISA tersebut dapat disimpulkan bahwa Indonesia berada dititik rendah literasi. Pemerintah Indonesia harus segera mengatasinya.

Pemerintah melalui Kementerian Pendidikan dan Kebudayaan (Kemendikbud) mencoba membuat solusi tersebut, yaitu dengan membuat suatu gerakan bernama Gerakan Literasi Bangsa (GLB). GLB dibuat dengan tujuan menumbuhkan budi pekerti remaja melalui budaya literasi membaca dan menulis. Dalam program tersebut, pemerintah berupaya menumbuhkan kesadaran kepada remaja melalui kebijakan atau kebiasaan membaca selama 15 menit sebelum proses pembelajaran dimulai atau dalam sehari minimal 15 menit melakukan kegiatan membaca.

Dalam kegiatan literasi membaca diharapkan pembaca mampu bernalar dan memahami isi bacaan sehingga mampu membantu kegiatan menulis menjadi lebih mudah. Tidak heran jika dalam berbagai hasil penelitian menunjukkan bahwa kemampuan menulis masih rendah karena budaya baca dan budaya nalar yang belum baik (Budiana, Indrowaty, \& Ambarastuti, 2018). Untuk dapat menguasai keempat keterampilan bahasa tersebut, pembelajaran bahasa juga dapat dikuasai dengan menggunakan berbagai pendekatan. Salah satunya dengan menggunakan pendekatan berbasis teks (genre based approach).

Dalam mencari kebaruan (state of the art), peneliti melakukan observasi terhadap beberapa artikel yang terkait dengan judul penelitian ini, yakni deiksis. Observasi dilakukan dengan melihat tujuan penelitian, kota dan negara peneliti sebelumnya, partisipan, kekuatan, dan kelemahan. Nursalim \& Alam (2019) mengkaji bentuk, fungsi, dan makna deiksis persona dalam cerpen di surat kabar Republika. Artikel ini diterbitkan di Cirebon, Indonesia. Partisipan dalam penelitian ini adalah cerpen dalam surat kabar Republika edisi Januari 2017. Kekuatan artikel ini adalah terdapat tiga fungsi pemakaian deiksis persona dalam cerpen di surat kabar Republika, yakni: merujuk kepada orang yang berbicara, merujuk kepada orang yang diajak berbicara, dan merujuk kepada orang yang dibicarakan. Kekurangan dari artikel ini adalah hanya mengkaji cerpen dari satu surat kabar.

Ferrari (2016) menganalisis kata ganti orang pertama dan orang kedua tunggal dalam bahasa Inggris dan bahasa Portugis Brazil. Artikel ini diterbitkan di Rio de Janeiro, Brazil. Partisipan dalam artikel ini adalah kumpulan tulisan elektronik, seperti the British National Corpus untuk bahasa Inggris dan the Portuguese Corpus untuk bahasa Portugis Brazil. Kekuatan artikel ini adalah kata ganti orang pertama tunggal dan kata ganti orang kedua tunggal merupakan majemuk dan tepat untuk menghasilkan makna. Pertama, kata ganti orang pertama dan orang kedua tunggal memiliki makna konvensional. Kedua, sebagai petunjuk bahwa kata ganti juga menunjukkan arti nonkonvensional. Kelemahan dalam artikel ini adalah terjadi campur kode antara bahasa Inggris dan bahasa Portugis Brazil.

Berdasarkan hasil dari observasi beberapa penelitian terdahulu, yang menjadi kebaruan (state of the art) antara penelitian ini dan penelitian terdahulu adalah masih terbatas penelitian tentang deiksis dalam buku ajar. Terutama penelitian deiksis dalam buku ajar pembelajaran BIPA. Oleh karena itu, peneliti memilih judul "Deiksis dalam Buku Ajar Sahabatku Indonesia Tingkat B2".

Levinson (1983) berpendapat bahwa cara yang paling nyata hubungan antara bahasa dan konteks tergambar dalam bahasa-bahasa itu sendiri dan 
perwujudan deiksis. Deiksis menjadi sesuatu yang penting untuk memahami bahasa dan konteks (Suparno, 2016). Sejalan dengan itu, Riemer (2010) mendefinisikan deiksis merupakan kata acuan dari beberapa aspek pada konteks tuturan yang memiliki makna penting. Jika ingin memahami sebuah tuturan, harus dilihat konteks dan kata acuan/ deiksis yang digunakan. Levinson (1983) mengemukakan bahwa deiksis persona secara langsung diwujudkan dalam kategori gramatikal tentang persona (orang) menjadi persona pertama, persona kedua, dan persona ketiga. Berbeda dengan persona pertama dan persona kedua, persona ketiga tidak berhubungan langsung dengan peran partisipan apapun dalam tiap peristiwa tutur. Dalam deiksis persona yang menjadi kriteria adalah peran partisipan, yaitu: peran sebagai penutur (orang kesatu), pendengar (orang kedua), dan yang dibicarakan menjadi orang ketiga.

Cara yang lazim untuk mengkodekan deiksis persona adalah dengan memakai pronomina persona (kata ganti orang), seperti: saya, aku, kamu, engkau, kau, ia, dia, beliau, kami, kita, mereka, atau memakai nama diri seperti Saudara, Bapak, Ibu, dan sebagainya (Darsita, 2015). Selain itu, deiksis persona juga mencakup bentuk-bentuk lain dari pronomina seperti $k u-,-k u,-m u,-n y a$, dan kau. Deiksis persona berhubungan dengan pemahaman mengenai peserta dalam situasi pertuturan di mana tuturan tersebut dituturkan.

Kategori dari deiksis persona dibagi ke dalam tiga bagian, yakni: kategori orang pertama, orang kedua, dan orang ketiga. Orang pertama adalah tata bahasa dari referensi pembicara sendiri. Orang kedua adalah pemahaman pada referensi pembicara pada satu tujuan atau lebih. Orang ketiga adalah pemahaman referensi untuk orang, entitas penutur dan mitra tutur dari tuturan tersebut. Masing-masing kategori deiksis persona tersebut terdiri atas tunggal dan jamak.

Richards (2001) menyatakan bahwa buku teks yang digunakan dalam suatu program bahasa berbeda-beda. Maksudnya, buku teks yang digunakan dalam pembelajaran bahasa berbeda-beda bergantung pada program pembelajaran. Sejalan dengan itu, Brown (2000) menyatakan bahwa bentuk materi pendukung yang paling nyata dan umum untuk pembelajaran bahasa adalah buku teks. Dalam pembelajaran BIPA, buku ajar yang digunakan menggunakan empat keterampilan plus, yaitu keterampilan menyimak, keterampilan membaca, keterampilan menulis, keterampilan berbicara, catatan budaya, dan tata bahasa. Buku ajar dapat ditambah dengan media pembelajaran agar lebih efektif.

BIPA merupakan pembelajaran bahasa Indonesia yang ditujukan untuk pemelajar asing atau bukan orang Indonesia. BIPA dipandang lebih kepada siapa pemelajarnya. Muliastuti (2017) menjelaskan bahwa pembelajaran BIPA lebih kompleks dan rumit karena siswa asing yang belajar BIPA dapat berasal dari berbagai negara. Hal ini diperkuat dengan pendapat Damaianti (2016), BIPA merupakan suatu tuntutan zaman karena di era kesejagatan ini kancah pergaulan antarbangsa menempatkan bahasa Indonesia sebagai bahasa penting di dunia. Oleh karena itu, pembelajaran BIPA tidak hanya bahasa yang dipelajari, tetapi juga budaya Indonesia. Pada dasarnya mempelajari bahasa berkaitan erat dengan budaya Indonesia sehingga membuat pemelajar lebih komprehensif mengenal Indonesia (Zaenuri \& Yuniawan, 2018).

\section{METODE}

Metode penelitian yang dilakukan adalah metode analisis isi dengan pendekatan deskriptif kualitatif pada bagian dialog dari buku ajar Sahabatku 
Indonesia tingkat B2. Data dalam penelitian ini adalah kalimat yang mengandung deiksis persona dalam dialog pada buku ajar Sahabatku Indonesia tingkat B2. Sumber data yang digunakan dalam penelitian ini adalah buku ajar Sahabatku Indonesia tingkat B2. Penelitian ini telah dilakukan di perpustakaan UNJ pada bulan Agustus 2019 s.d. Oktober 2019.

Teknik pengumpulan data meliputi dokumen yang berisi data jenis-jenis deiksis persona dan retorika deiksis yang ada dalam tujuh wacana dialog buku ajar BIPA Sahabatku Indonesia tingkat B2. Pengumpulan data diperoleh melalui langkah-langkah: (1) membaca buku ajar BIPA Sahabatku Indonesia tingkat B2, (2) menandai kalimat yang mengandung deiksis persona pada bagian dialog buku ajar BIPA Sahabatku Indonesia tingkat B2, (3) memilih dan mengidentifikasi kalimat yang mengandung deiksis persona pada bagian dialog buku ajar Sahabatku Indonesia tingkat B2, (4) menandai kalimat yang mengandung retorika deiksis, dan (5) mengidentifikasi kalimat yang mengandung deiksis persona dan retorika deiksis.

Sugiyono (2012) menyebutkan bahwa analisis data dilakukan dengan mengorganisasikan data, menjabarkannya ke dalam unit-unit, melakukan sintesis, menyusun ke dalam pola, memilih mana yang penting dan yang akan dipelajari, dan membuat kesimpulan yang dapat diceritakan kepada orang lain. Adapun langkah-langkah analisis data penelitian, meliputi: (1) membaca dan menelaah secara kritis dan berulang-ulang buku ajar BIPA Sahabatku Indonesia tingkat B2, (2) menandai kalimat yang mengandung deiksis persona dan retorika deiksis dalam dialog buku ajar BIPA Sahabatku Indonesia tingkat B2, (3) menyusun dan mengategorikan kalimat-kalimat yang mengandung deiksis persona dalam buku ajar BIPA Sahabatku Indonesia tingkat B2 berdasarkan jenis deiksis persona sesuai dengan tabel instrumen penelitian.

Tabel 1. Tabel Instrumen Penelitian Jenis-Jenis Deiksis Persona

\begin{tabular}{cccccc}
\hline No. Konteks & $\begin{array}{c}\text { Deiksis Persona } \\
\text { Pertama }\end{array}$ & $\begin{array}{c}\text { Deiksis Persona } \\
\text { Kedua }\end{array}$ & $\begin{array}{c}\text { Deiksis Persona } \\
\text { Ketiga }\end{array}$ & $\begin{array}{c}\text { Analisis } \\
\text { Data }\end{array}$ \\
& Tunggal Jamak & Tunggal Jamak & Tunggal Jamak &
\end{tabular}

\section{HASIL DAN PEMBAHASAN}

Jenis-jenis deiksis persona yang ditemukan dalam penelitian ini sejumlah 102 data. Data tersebut terdiri atas 55 data $(53,92 \%)$ deiksis persona pertama tunggal, 4 data $(3,92 \%)$ deiksis persona pertama jamak, 29 data $(28,43 \%)$ deiksis persona kedua tunggal, $0(0 \%)$ deiksis persona kedua jamak, 8 data $(7,84 \%)$ deiksis persona ketiga tunggal, dan 6 data $(5,88 \%)$ deiksis persona ketiga jamak. Dari paparan tersebut dapat dilihat bahwa deiksis persona pertama tunggal merupakan deiksis yang dominan muncul dalam penelitian ini. 


\section{Deiksis Persona dalam Buku Ajar BIPA Sahabatku Indonesia tingkat B2}

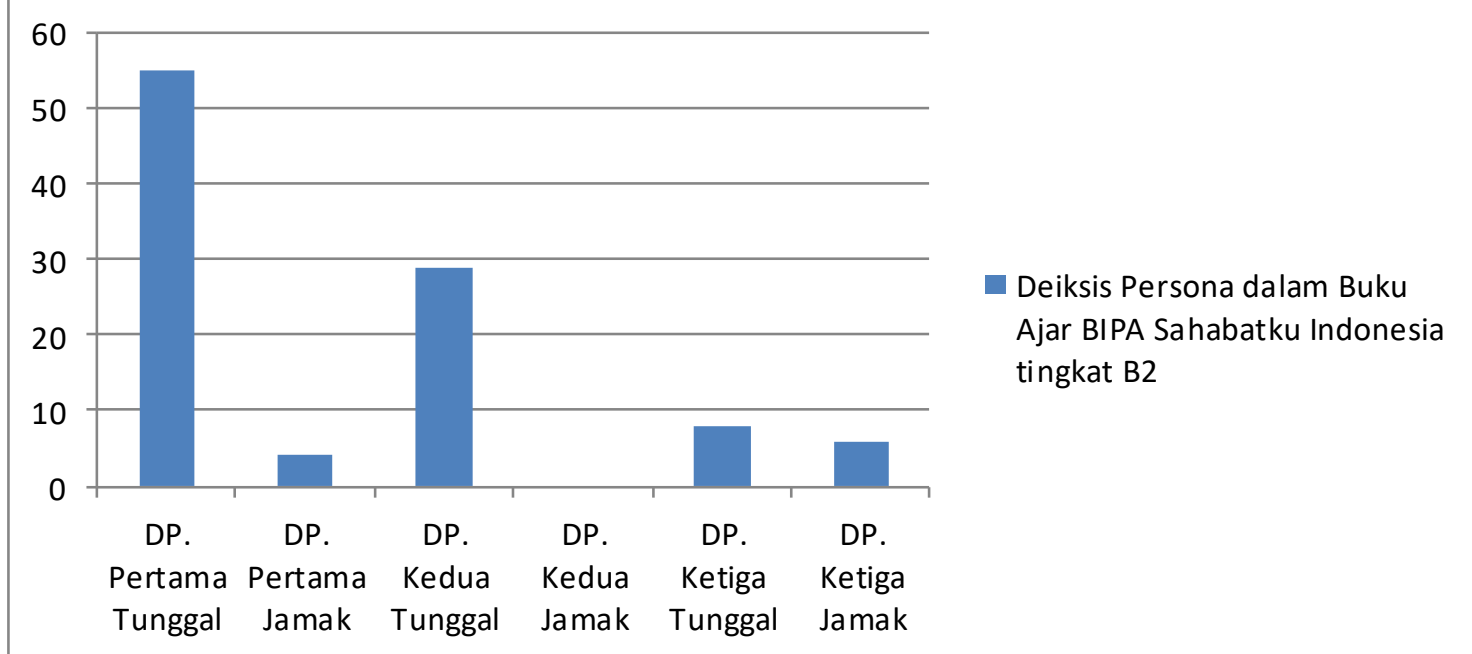

\section{Gambar 1. Deiksis Persona dalam Bukuk Ajar BIPA Sahabat Indonesia Tingkat B2}

Retorika deiksis yang ditemukan dalam buku ajar Sahabatku Indonesia tingkat B2 sebanyak 71 data. Dalam aspek lisan banyak menggunakan kata kerja dasar, menggunakan kata $a k u$ sebagai kata ganti orang pertama tunggal, dan tidak memerlukan kata tanya pada kalimat tanya ya/tidak hanya melakukan penekanan pada akhir kalimat. Hal tersebut bertujuan agar lebih efektif dan pesan dalam suatu tuturan dapat diterima oleh lawan tutur.

\section{Jenis-Jenis Deiksis Persona}

Deiksis persona melibatkan identifikasi peserta atau orang dalam sebuah teks (Pratiwi, 2018). Deiksis persona terdiri atas enam jenis, yaitu: deiksis persona tunggal, deiksis persona pertama jamak, deiksis persona kedua tunggal, deiksis persona kedua jamak, deiksis persona ketiga tunggal, dan deiksis persona ketiga jamak. Deiksis persona yang paling dominan dalam buku ajar BIPA Sahabatku Indonesia tingkat B2 adalah deiksis persona tunggal karena dalam sebuah konteks sehari-hari memang sering digunakan. Hal ini dapat dilihat dari data berikut.

(1) Rina : "Baik, bagaimana dengan kamu?"

Riri : "Aku juga baik, oh iya kemarin aku melihat Ayahmu, ia pergi ke arah laut, apa yang akan dikerjaannya?" (h.10)

(2) Rina : "Baik, bagaimana dengan kamu?"

Riri : "Aku juga baik, oh iya kemarin $a k u$ melihat Ayahmu, ia pergi ke arah laut, apa yang akan dikerjakannya?" (h.10)

(3) Rina : "Oh, Ayahku memang bekerja di laut, ia seorang nelayan. Kalau Ayahmu bekerja di mana?"

Riri : "Ayahku juga seorang nelayan. Jika Ayahku pulang, ia selalu membawa banyak ikan." (h.10)

Berdasarkan data (1), (2), dan (3) dapat dilihat bahwa terdapat penggunaan deiksis persona pertama tunggal. Data (1) ditandai dengan $a k u$ yang mengacu kepada Riri yang menyatakan ia dalam keadaan sehat. Data (2) ditandai dengan 
$a k u$ yang mengacu kepada Riri melihat Ayah Rina kemarin menuju arah laut. Kemudian, data (3) ditandai dengan aku yang mengacu kepada ayahnya Riri juga seorang nelayan. Pekerjaan Ayah Riri sama seperti pekerjaan Ayah Rina.

Deiksis persona pertama jamak dapat dilihat sebagai berikut.

(4) Riri : "Hai Rina, apa kabar? Sudah lama sekali kita tidak bertemu?" Rina : "Baik, bagaimana dengan kamu?" (h.10)

(5) Udin : "Aku diberi tugas untuk membuat karangan tentang profesi yang akan aku tekuni, sedangkan aku ingin menjadi atlet voli. Apakah atlet juga sebuah profesi?"

Andi ; "Oh tentu. Atlet, guru, petani, penyanyi juga merupakan sebuah profesi kalau kita memang sungguh-sungguh ingin menekuninya." (h. 23)

(6) Simon : "Bagaimana jika kita berkunjung ke tempat-tempat bersejarah yang memiliki ciri khas bangunan yang unik?"

Syifa : "Mmm.. sepertinya Vila Isola dan Gedung Sate akan menjadi pilihan yang tepat." (h.64)

Berdasarkan data (4), (5), dan (6) menggunakan kata kita untuk menunjukkan deiksis persona pertama jamak tetapi memiliki makna yang berbeda-beda. Makna kita dalam data (4) adalah Riri dan Rina. Mereka adalah teman dan sudah lama tidak bertemu. Makna kita dalam data (5) adalah Udin, Andi, dan orang yang menekuni suatu profesi. Sementara itu, makna kita dalam data (6) adalah Simon dkk. yang akan berkunjung ke Bandung.

Deiksis persona kedua tunggal dapat dilihat sebagai berikut.

(7) Rina : "Baik, bagaimana dengan kamu?"

Riri : "Aku juga baik, oh iya kemarin aku melihat Ayahmu, ia pergi ke arah laut, apa yang akan dikerjakannya?" (h.10)

Rina : "Baik, bagaimana dengan kamu?"

Riri : "Aku juga baik, oh iya kemarin aku melihat Ayahmu, ia pergi ke arah laut, apa yang akan dikerjakannya?" (h.10)

(9) Riri : "Aku juga baik, oh iya kemarin aku melihat Ayahmu, ia pergi ke arah laut, apa yang akan dikerjakannya?"

Rina : "Oh, Ayahku memang bekerja di laut, ia seorang nelayan. Kalau Ayahmu bekerja di mana?" (h.10)

Berdasarkan data (7), (8), dan (9) dapat kita lihat bahwa penggunaan kata kamu dan $-m u$ memiliki makna yang berbeda. Data (7) kata kamu mengacu kepada Riri. Rina menanyakan bagaimana kabar Riri. Data (8) kata Ayahmu mengacu kepada Ayah Rina. Kemarin, Riri melihat Ayah Rina berjalan ke arah laut dan ia bertanya kepada Rina apa yang akan dilakukan oleh Ayah Rina. Selanjutnya, data (9) menggunakan kata Ayahmu yang mengacu kepada Ayah Riri. Rina menanyakan kepada Riri apa pekerjaan Ayah Riri.

Deiksis persona ketiga tunggal dapat dilihat sebagai berikut.

(10) Rina : "Baik, bagaimana dengan kamu?"

Riri : "Aku juga baik, oh iya kemarin aku melihat Ayahmu, ia pergi ke arah laut, apa yang akan dikerjakannya?" (h.10)

(11) Rina : "Baik, bagaimana dengan kamu?"

Riri : "Aku juga baik, oh iya kemarin aku melihat Ayahmu, ia pergi ke arah laut, apa yang akan dikerjakannya?" (h.10) 
(12) Dina : "Besok keponakan saya akan ikut lomba peragaan busana di sekolahnya dalam acara memperingati Hari Kartini. Saya ingin kamu mendandaninya, Gi."

Anggi: “Oh iya, besok tanggal 21 April ya?" (h.110)

Berdasarkan data (10, (11), dan (12) merupakan deiksis persona ketiga jamak. Hal ini ditandai dengan penggunaan kata ia dan -nya. Data (10) dan data (11) mengacu kepada Ayah Rina. Sementara itu, data (12) mengacu kepada keponakan Dina yang akan mengikuti lomba peragaan busana.

Deiksis persona ketiga jamak dalam buku ajar BIPA Sahabatku Indonesia tingkat B2 dapat dilihat sebagai berikut.

(13) Prisca : "Menurut pendapat saya, sebaiknya orang tuamu mengizinkanmu untuk belajar pada siang hari dan tidak membantu mereka."

Andi : "Saya mempunyai pemikiran yang berbeda. Menurut saya, sebagai seorang anak saya harus membantu mereka mencari uang. Saya tidak tega melihat mereka harus bekerja keras demi diri saya sendiri." (h.72)

(14) Prisca : "Menurut pendapat saya, sebaiknya orang tuamu mengizinkanmu untuk belajar pada siang hari dan tidak membantu mereka."

Andi : "Saya mempunyai pemikiran yang berbeda. Menurut saya, sebagai seorang anak saya harus membantu mereka mencari uang. Saya tidak tega melihat mereka harus bekerja keras demi diri saya sendiri." (h.72)

(15) Prisca : "Ya benar Andi. Apakah orang tuamu memaksa kamu untuk membantu mereka?"

Andi : "Mereka hanya menyuruh saya untuk membantu berdagang pada hari Minggu. Namun, pada hari Senin hingga Sabtu saya disuruh bersekolah dan belajar." (h. 72)

Kata mereka dalam data (13), (14), dan (15) mengacu kepada orang tua Andi dengan konteks yang berbeda. Data (13) memiliki konteks Prisca memberikan saran kepada Andi agar orang tua Andi mengizinkan Andi untuk belajar pada siang hari dan tidak membantu mereka berdagang. Data (14) memiliki konteks Andi berpikir bahwa seorang anak itu harus membantu orang tuanya mencari uang. Selanjutnya, untuk data (15) memiliki konteks Prisca bertanya kepada Andi apakah orang tua Andi memaksa Andi untuk membantu mereka atau tidak.

\section{Retorika Deiksis}

Retorika adalah konteks natural dari orang, kejadian, objek, hubungan, dan urgensi yang sangat mengundang sebuah tuturan (Beasley dalam Ivanova, 2016). Retorika memberi bimbingan tentang bagaimana memanfaatkan bahasa dalam kegiatan bertutur. Jangkauan bimbingan retorika yaitu (1) memilih ragam bahasa, (2) memilih materi bahasa (seperti kata, istilah, ungkapan, dan kalimat) yang berimbang dengan kebutuhan masyarakat pemakainya, (3) menata materi bahasa, dan (4) memilih gaya bahasa.

Berdasarkan hasil penelitian, dalam buku ajar BIPA Sahabatku Indonesia tingkat B2 terdapat 71 data retorika deiksis. Retorika deiksis tersebut meliputi: (1) dalam aspek lisan menggunakan kata kerja dasar, (2) menggunakan kata aku 
sebagai kata ganti orang pertama tunggal, dan (3) tidak memerlukan kata tanya pada kalimat tanya ya/ tidak. Berikut ini data-datanya.

(1) Aku juga baik, oh iya kemarin aku melihat Ayahmu, ia pergi ke arah laut, apa yang akan dikerjakannya? (h.10)

Aku juga baik, oia kemarin aku lihat Ayahmu! Ia pergi ke arah laut. Mau ngapain?

Aspek lisan dalam data (1), masyarakat Indonesia dalam sehari-hari banyak menggunakan kata kerja dasar, seperti lihat, baca, tulis. Sementara itu kalimat mau ngapain? Lebih sederhana daripada apa yang akan dikerjakannya? Selain itu, dalam ragam informal menggunakan kata aku sebagai kata ganti orang pertama tunggal. Bukan menggunakan kata Ayahku juga seorang nelayan. Jika Ayahku pulang, ia selalu membawa banyak ikan. (h.10)

(2) Ayahku juga seorang nelayan. Jika Ayahku pulang, ia selalu membawa banyak ikan. (h.10)

Ayahku juga nelayan. Kalo Ayahku pulang, ia bawa ikan banyak.

Aspek lisan dalam data (2) tidak memerlukan kara seorang untuk menjelaskan profesi. Sementara itu, kata kerja dasar lebih sering dipakai dalam ragam informal, seperti kata bawa. saya.

(3) Halo, teman-teman saya berencana akan melakukan wisata ke beberapa tempat bersejarah di Bandung. Apakah teman-teman akan ikut? (h.64)

Halo, teman-teman saya rencana akan pergi ke beberapa tempat bersejarah di Bandung. Pada mau ikut gak?

Aspek lisan yang digunakan dalam data (3) adalah menggunakan kata rencana bukan berencana agar pesan dalam kalimat data (39) dapat lebih mudah diterima. Kemudian, kalimat ajakan yang digunakan adalah pada mau ikut gak? bukan apakah teman-teman akan ikut?. Hal ini agar lebih komunikatif.

(4) Ya, benar Andi. Apakah orang tuamu memaksa kamu untuk membantu mereka? (h.72)

Ya, benar Andi. Orang tuamu maksa kamu untuk bantu mereka?

Pertanyaan ya/ tidak dalam aspek lisan tidak dipakai, hanya penekanan dalam akhir kalimat tanya.

(5) Saya juga. Meskipun hanya dilakukan setahun sekali, tapi hal ini dapat membantu anak-anak mengembangkan keterampilannya. (h.111)

Aku juga. Meskipun cuma setahun sekali, tapi ini dapat bantu anak-anak mengembangkan keterampilannya.

Aspek lisan dalam data (5) menggunakan kata ganti orang pertama tunggal $a k u$. Selain itu, data (68) menggunakan kata kerja dasar, seperti bantu.

\section{SIMPULAN}

Berdasarkan hasil dan pembahasan dapat disimpulkan bahwa (1) deiksis persona pertama tunggal merupakan deiksis persona yang dominan dalam buku ajar BIPA Sahabatku Indonesia tingkat B2 yakni sebesar 53,92\%, (2) deiksis persona kedua tunggal merupakan tingkat kedua yang sering muncul dalam buku ajar BIPA Sahabatku Indonesia tingkat B2 yakni sebesar 28,43\%, dan (3) deiksis persona ketiga tunggal berada di urutan ketiga yang sering muncul dalam buku ajar BIPA Sahabatku Indonesia tingkat B2 yakni 7,84\%. Hal tersebut menunjukkan bahwa deiksis persona pertama tunggal paling sering digunakan sebagai rujukan persona dalam kehidupan sehari-hari. Sementara itu, retorika deiksis yang ditemukan dalam buku ajar BIPA Sahabatku Indonesia tingkat B2 
ada 71 data. Berdasarkan hasil penelitian, dalam aspek lisan banyak menggunakan kata kerja dasar, kata aku sebagai kata ganti orang pertama tunggal, dan tidak memerlukan kata tanya pada kalimat tanya ya atau tidak hanya melakukan penekanan pada akhir kalimat. Hal tersebut bertujuan agar lebih efektif dan komunikatif.

\section{DAFTAR PUSTAKA}

Brown, D. (2000). Teaching by Principles_- Brown H. Douglas II.pdf.

Budiana, N., Indrowaty, S. A., \& Ambarastuti, R. D. (2018). Pengembangan Buku Teks BIPA Berbasis Multikulturalisme bagi Penutur Asing Tingkat Pemula. Diglossia, 9(2), 108-122.

Damaianti, V. S. (2016). Internalisasi Wawasan Kebangsaan dalam Menguatkan Citra Diri Bangsa Para Pengajar BIPA. In Seminar Kepakaran BIPA 1 (p. 26).

Darsita, D. (2015). “ Deiksis" dalam Kumpulan Cerpen Al -Kabuus Tinjauan Sosiopragmatik. Al-Turāsं, XXI(2), 343-365.

Fariqoh, R. (2016). Pengembangan Bahan Ajar Membaca untuk Pembelajar Bahasa Indonesia Penutur Asing Tingkat Dasar. Riksa Bahasa, 2(2), 219223.

Ferrari, L. (2016). Deixis and Multiple Blends: The Role of Recursion in Meaning Construction. Acta Scientiarum. Language and Culture, 38, 153-159. https://doi.org/10.4025/actascilangcult.v38i2.29400

Ivanova, A. (2016). Deixis and Its Role in Defining Rhetorical Space. Revista Signos Estudios De Linguistica, 49(92), 329-349. https://doi.org/10.4067/S0718-09342016000300004

Levinson, S. C. (1983). Pragmatics. Cambridge University Press. https://doi.org/10.1017/CBO9780511813313

Muliastuti, L. (2017). Bahasa Indonesia bagi Penutur Asing. Jakarta: Yayasan Pusaka Obor Indonesia.

Mulyaningsih, I., Suwandi, S., Setiawan, B., \& Rohmadi, M. (2018). PARMI (Production, Attention, Retention, Motivation, and Innovation): an Alternative to Improving Scientific Writing Skills. Lingua Cultura, 12(4), 317-321. https://doi.org/10.21512/lc.v12i4.4159

Nursalim, M. P., \& Alam, S. N. (2019). Pemakaian Deiksis Persona dalam Cerpen di Harian Republika. Deiksis, 11, 121-129.

Pratiwi, S. (2018). Person Deixis in English Translation of Summarized Shahih Al-Bukhari Hadith in the Book of As-Salat. Advances in Language and Literary Studies, 9(1), 40-43.

Richards, J. C. (2001). Curriculum Development in Language Teaching. United States of America: Cambridge University Press.

Riemer, N. (2010). Introducing Semantics (Pertama). New York: Cambridge University Press.

Sugiyono. (2012). Metode Penelitian Pendidikan. Bandung: Alfabeta.

Suparno, D. (2016). "Deiksis" dalam Nazam Tarekat Karya K.H. Ahmad Ar-Rifai Kalisasak: Tinjauan Pragmatik. Dialektika: Jurnal Bahasa, Sastra, Dan Pendidikan Bahasa Dan Sastra Indonesia, 3(2), 153-172.

Suyitno, I. (2007). Pengembangan Bahan Ajar Bahasa Indonesia untuk Penutur Asing (BIPA) Berdasarkan Hasil Analisis Kebutuhan Belajar. Wacana, 9(1), 62-78. 


\section{Indonesian Language Education and Literature}

e-ISSN: 2502-2261

http://www.syekhnurjati.ac.id/jurnal/index.php/jeill/

Vol. 5, No. 2, Juli 2020, 160 - 170

TIMSS, \& PIRLS. (2019). Result PIRLS Database Lates a Test News.

Zaenuri, M., \& Yuniawan, T. (2018). Pengembangan Laman Media Audiovisual Bermuatan Materi Kebudayaan Indonesia sebagai Media Pembelajaran BIPA. Jurnal Pendidikan Bahasa Dan Sastra Indonesia, 7(1), 60-65. 